\title{
An orbital fistula complicating anaerobic frontal sinusitis and osteomyelitis
}

\author{
H.J. SIMONSZ, H.J.F. PEETERS and G.M. BLEEKER
}

Orbita Centrum, Ophthalmological Hospital, Wilhelmina Gasthuis, Amsterdam, The Netherlands

Keywords: sinusitis, anaerobic infection, orbital cellulitis

\begin{abstract}
A patient is described with an orbital fistula complicating frontal sinusitis and osteomyelitis of the frontal bone. The fistula was excised, but a fortnight later an acute exacerbation occurred. From the discharging pus a Staphylococcus aureus was cultured and from mucosa obtained during surgery a microaerophilic Streptococcus. These findings led to the diagnosis: synergistic bacterial inflammation of the frontal sinus, with osteomyelitis and orbital cellulitis.
\end{abstract}

\section{Case report}

A 20-year-old soldier visited the Outpatient Department of the Wilhelmina Gasthuis in September 1980. He presented a fistula above the right eyelid existing for five months, which opened periodically discharging pus and blood. He had suffered a fractured nose 18 months previously, with subsequent complaints of maxillary sinusitis. A few months later the right upper eyelid became swollen and a few months after that the swelling perforated and pus and blood were discharged. The patient was treated in another hospital for the maxillary sinusitis by a Caldwell-Luc operation. Antibiotics were administered for the fistula.

On admission to our hospital a month after the first examination the patient presented a fistula opening above the right eyelid and below the right ear a solid lymph node of $2 \mathrm{~cm}$ diameter was palpated. A culture taken from the opening of the fistula yielded a beta-haemolytic and a green colouring Streptococcus. X-rays of the skull and orbit showed areas of decreased density in the frontal bone on both sides with a very vague superior margin on the right, indicating a destructive bone lesion. The fistula was excised and was found to originate in the frontal sinus, from which a biopsy was taken. Pathological examination showed a chronic, aspecific, inflammatory process; bacterial culture was negative. Blood examination showed raised $\operatorname{IgA}$ and a low number of T-cells.

A fortnight later the patient was again admitted with an intensely swollen right upper eyelid and eyebrow. He was unable to open his eye and there was continuous discharge of pus and blood from the operation wound. Patient had tachycardia, no fever and a second degree, apical, systolic murmur. The 

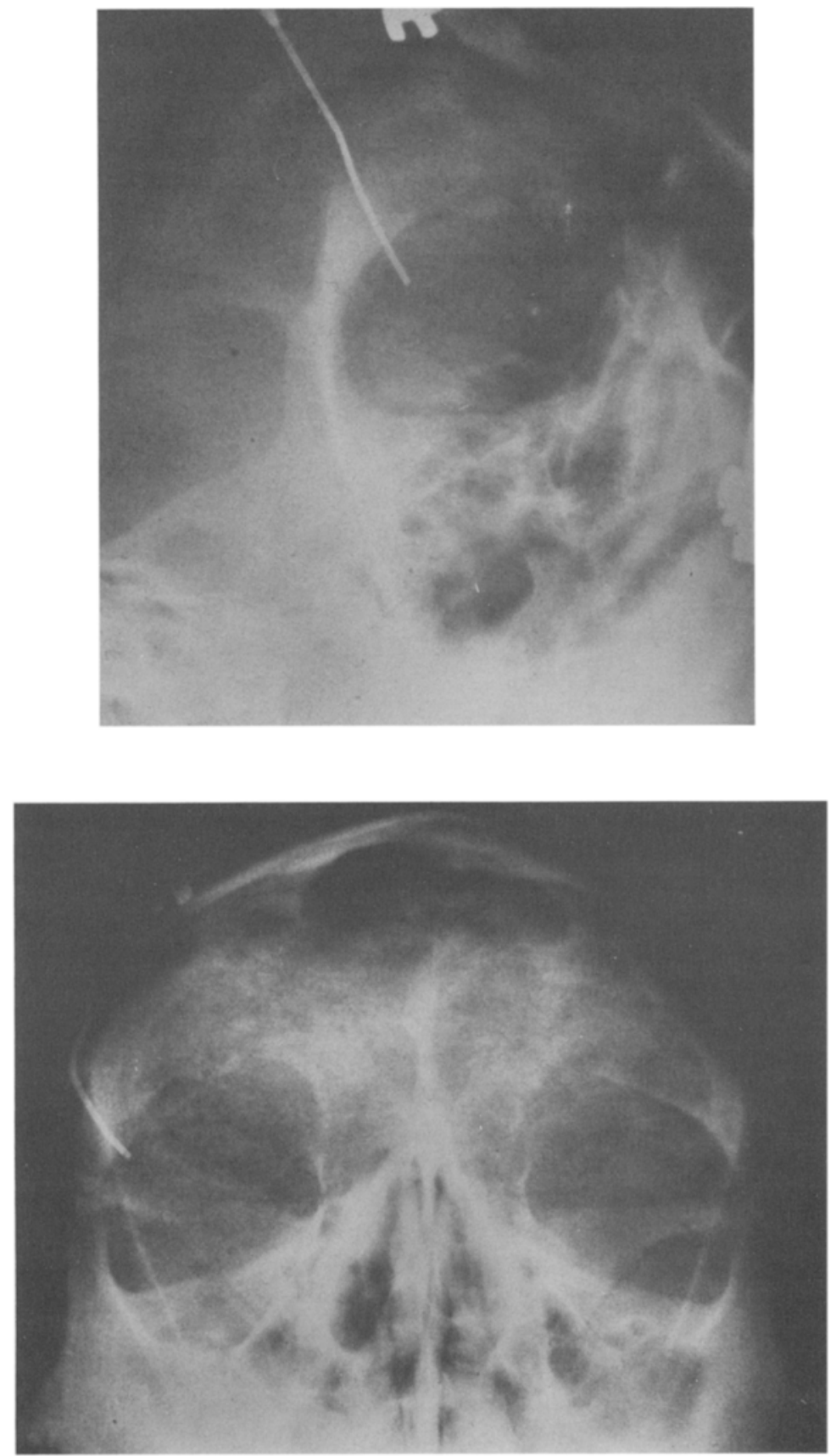

Figures. X-ray photographs of skull of patient: the right superior orbital margin is discontinuous 
patient was treated with penicillin $\mathrm{V}$ orally and the oedema and discharge of pus subsided. From the pus a penicillinase forming Straphylococcus aureus was cultured. Both frontal sinuses were opened surgically; the right sinus contained pus, the left thickened mucosa. On anaerobic culture a microaerophilic Streptococcus was found. Postoperatively penicillin G (6 million units per day) was administered intravenously. The anaemia which had developed was treated with iron sulphate. Echocardiography showed that the murmur was caused by the anaemia, not by endocarditis. The patient was discharged in good health.

The diagnosis was: chronic, anaerobic, frontal sinusitis from microaerophilic Streptococci, complicated by orbital cellulitis and osteomyelitis. The last exacerbation was probably due to a synergistic bacterial infection, a microaerophilic Streptococcus in combination with a Staphylococcus aureus.

\section{Pathophysiology of the diseased sinus}

What are the conditions for the growth of anaerobes such as the microaerophilic Streptococcus?

First of all, a low oxygen concentration is required. Oxygen which is aspirated from the nose through the ostium, is continuously absorbed by the mucosa of the sinus (Aust et al., 1979). When the ostium is obstructed, the pO2 decreases in approximately an hour from 135 to $110 \mathrm{~mm} \mathrm{Hg}$. In sinusitis, the pO2 not only decreases because of ostium-obstruction, but because of oxygen consumption by bacteria and inflammatory cells as well. Carenfelt and Lundberg (1978) found in sinusitis a pO2 of $90 \mathrm{~mm} \mathrm{Hg}$ in serous secretions and a pO2 of approximately $1 \mathrm{~mm} \mathrm{Hg}$ in purulent secretions. A low pO2 not only stimulates the growth of anaerobes but also inhibits the bactericidal action of the leucocytes.

A second condition for the growth of anaerobes is a low redox potential of tissue. The redox potential is the voltage at which a substance will give up or take up electrons. Substances with a high redox potential oxidate more readily; substances with a low redox potential reduce more readily. Healthy tissue has a redox potential of $+120 \mathrm{mV}$, which provides a good protection against anaerobic infections. In the intestines, in necrotic tissue and in abscesses the redox potential is $-150 \mathrm{mV}$ to $-250 \mathrm{mV}$ and anaerobes flourish there (Sherwood \& Barlett, 1974). The redox potential decreases by diminished blood supply, growth of facultative anaerobes, foreign bodies, necrosis and surgical procedures (Levison, 1973). The first two factors are present in sinusitis.

\section{Incidence of anaerobic sinusitis}

Karma et al. (1979) cultured anaerobes from the mucosa of infected maxillary sinuses in $18 \%$ of sinusitis cases (61 patients); van Cauwenberge (1975) 25\% 
(180 patients); Frederick \& Braude (1974) 43\% (83 patients). The anaerobic bacteria found were microaerophilic Streptococci in $12 \%, 33 \%$ and $35 \%$.

\section{Clinical signs and complications}

The general characteristics of anaerobic infections (Jawetz, 1977; Levison, 1973) are:

(1) the process is in an enclosed space.

(2) the pus produces a foul odor.

(3) cultures are repeatedly negative.

(4) the inflammation is in the proximity of a mucous membrane.

(5) there is often more than one anaerobe involved.

(6) gas is produced by Clostridia, Bacteriodes and anaerobic Streptococci.

(7) septic thrombophlebitis and metastatic infections are frequent.

(8) all anaerobes are sensitive to penicillin $G$ except Bacteriodes fragilis, which occurs frequently, however.

In our patient six of these characteristics were present.

The complications of chronic sinusitis are orbital cellulitis, osteomyelitis, meningitis, extradural abscess and abscess of the brain. Smith and Spencer (1948) defined the following stages of orbital cellulitis:

(1) oedema of the eyelids.

(2) oedema of the orbital contents, exophthalmos, limitation of ocular movements.

(3) subperiostal abscess, which may rupture towards the eyelids.

(4) orbital abscess, exophthalmos, reduced vision and ophthalmoplegia.

(5) thrombosis of the cavernous sinus.

Interestingly, a microaerophilic Streptococcus and a Staphylococcus aureus were cultured in 2 out of 3 cases of osteomyelitis with sinusitis described by Thomas and $\mathrm{Nel}$ in 1977.

\section{Bacterial synergism}

A synergistic bacterial infection is a chronic infection caused by a microaerophilic Streptococcus and a facultatively anaerobic, haemolytic Staphylococcus aureus. The infection usually presents as a chronic, fistulating ulcer (Meleney's ulcer) or a chronic, progressive gangrene. The synergistic action of the two bacteria was discovered by Meleney in 1931 and was extensively investigated by Mergenhagen in 1958. He injected suspensions of the two bacteria subcutaneously in rabbits. Injection of a milliard of one sort or the other produced a local abscess. Injection of a milliard Staphylococci plus a hundred thousand Streptococci produced a progressive gangrene. In combination with sodium thioglycolate (a reducing agent), hyaluronidase or a 
filtrate of dead Staphylococci, again a hundred thousand microaerophilic Streptococci were sufficient to cause a spreading infection.

The hyaluronidase produced by the Staphylococcus depolymerizes the polysaccharides of the ground substance of connective tissue. This tissue destruction causes lowering of the redox potential and oxygen concentration and thus stimulates the growth of the Streptococcus. It is possible that there are other mechanisms as well (Mergenhagen et al., 1958). Moreover, in our opinion, the penicillinase which may be produced by the Staphylococcus could protect the Streptococcus against penicillin. This mechanism is assumed to be responsible for therapy resistant streptococcal infections of the throat (Dr. Hoogendijk, bacteriologist, personal communication).

Synergistic bacterial gangrene may also be caused by a combination of microaerophilic Streptococci and Proteus, or a combination of anaerobic Streptococci and Bacteriodes (Altemeier, 1972).

\section{Diagnosis}

The correct collection and transport of the culture specimen is of primary importance. A reliable and simple technique is aspirating the substance with a syringe, blowing out the air and pricking the needle into rubber. The definite culture must be made within fifteen minutes.

The substance can also be collected in tubes in which the oxygen has been replaced by nitrogen or carbon dioxide beforehand.

The best technique is the collection in a transport medium with a low redox potential, e.g. sodium thioglycolate or cysteine. This medium must be fresh to avoid too much prior oxygen absorption. It is possible to add a redox indicator like Resazarin, which turns pink if the redox potential rises above -42 mV (Finegold, 1979; Levison, 1973).

\section{Therapy}

Therapy is radical incision and drainage plus antibiotics. First choice is penicillin $G$, in severe infections up to 60 million units per day (Finegold, 1979). Second choices are erythromycin, clindamycin, metronidazol and chloramphenicol. Recently the benefits of hyperbaric oxygen therapy in the treatment of Meleney's ulcer have been established (Bakker, 1980).

\section{References}

Altemeier WA (1972) In: Davis-Christopher, Textbook of Surgery, ed.: Sabiston DC Philadelphia, Saunders, p. 335-338

Aust $R$ et al (1979) Studies of gas exchange and pressure in the maxillary sinus in normal and infected humans. Rhinology 17: 245-251

Bakker DJ (1980) De hyperbare-zuurstof behandeling van acuut huidgangreen (necrotiserende fasciitis en progressief bacterieel gangreen). Ned T Geneesk 124: $2164-2170$ 
Carenfelt $C$ and Lundberg $C$ (1978) The role of local gas composition in pathogenesis of maxillary sinus empyema. Acta Otolaryngol (Stockh) 85: 116-121

Cauwenberge P van (1975) The importance of anaerobic bacteria in paranasal sinusitis. Rhinology 13: $141-145$

Chandler JR et al. (1970) The pathogenesis of orbital complications in acute sinusitis. Laryngoscrope 80: $141-28$

Finegold SM (1979) In: Cecil, Textbook of Medicine, eds: Beeson, P.B, et al. Philadelphia, Saunders, p. 441-45.

Frederick $J$ and Braunde AI (1974) Anaerobic infection of the paranasal sinuses. New Engl J Med 290: 135-37

Jawetz E (1977) In: Current Medical Diagnosis and Treatment, eds.: Krupp, M.A. \& Chatton, M.J. Los Altos, California, Lange Medical Publications, p. 793-95

Karma $\mathrm{P}$ et al. (1979) Bacteria in chronic maxillary sinusitis. Arch Otolaryngol 105: $386-90$

Levison ME (1973) The importance of anaerobic bacteria in infectious diseases. Med Clin N Amer 57: 1015-27

Mergenhagen SE et al. (1958) Studies on synergistic infections,. 1. Experimental infections with anaerobic streptococci. J Infect Dis 103: $33-44$

Sherwood LC and Bartlett JG (1974) Anaerobic infections. New Engl J Med 290: 1177 $84,1237-45,1289-94$

Smith AF and Spencer JF (1948) Orbital complications resulting from lesions of the sinuses. Ann Otol Rhinol Laryngol. 57: 5-27

Thomas JN and Nell JR (1977) Acute spreading osteomyelitis of the skull complicating frontal sinusitis. J Laryngol. Otol 91: 55-62 